\title{
Experimental Investigation on the Mechanical Characteristics and Deformation Behaviour of Fractured Rock-Like Material with One Single Fissure under the Conventional Triaxial Compression
}

\author{
Taoli Xiao, Mei Huang ${ }^{(D)}$, Cheng Cheng, and Yunlong He \\ School of Urban Construction, Yangtze University, Jingzhou, Hubei Province, China \\ Correspondence should be addressed to Mei Huang; 201772357@yangtzeu.edu.cn
}

Received 4 November 2017; Revised 15 March 2018; Accepted 18 March 2018; Published 26 April 2018

Academic Editor: Salvatore Russo

Copyright (C) 2018 Taoli Xiao et al. This is an open access article distributed under the Creative Commons Attribution License, which permits unrestricted use, distribution, and reproduction in any medium, provided the original work is properly cited.

An experimental study was carried out on a rock-like material specimen containing a single fissure to investigate its mechanical characteristics and deformation behaviour under triaxial compression. The mechanical characteristics, such as peak strength and residual strength, are discussed. The confining pressure had a distinct effect on the ductility characteristics of the specimen. "A distinct stress drop" occurred in the early stage of the stress-strain curve when the length fissure was relatively long. The I-crack, II-crack, and III-crack are all observed under triaxial compression, and the III-crack is commonly observed under triaxial compression. Confining pressure plays an essential role in affecting the failure mode of the specimen. There are three kinds of failure modes in the triaxial compression experiment on a rock-like material specimen with one single fissure: tensileshear comprehensive failure, "X"-shaped shear failure, and shear failure along the fissure plane. These results are important and fundamental to understand the fracture mechanism of rock engineering.

\section{Introduction}

Rock is a complex media formed by geological processes in nature; the diagenetic backgrounds of different kinds of rock material or rock mass are varied. Rocks have been directly influenced by varied kinds of geological effects, such as ground-stress change and all kinds of geologic processes and weathering. Thus, there are varied kinds of microfissures or structural planes developed to different degrees that are common in rock. The mechanical properties and deformation characteristics of rock mass are significantly dependent on the microfissures or structural planes in rock mass, which has been validated with experiments by researchers such as Hoek, Brace, and Walsh on the basis of the Griffith Strength Theory.

Fractures in rock mass are one of the essential factors that strongly influence its mechanical properties and deformation laws. Yang and Jing [1] argued the mechanical parameters of flawed sandstone decrease with the increase of fissure length; furthermore, the parameters first decrease and then increase with increasing fissure angle. Based on the experimental research and PFC numerical simulation, Jin et al. [2] generalized that, with the increase of flaw angle, the tensile cracks initiate from gentle flaw and shear cracks emerge at tips of steep flaws. Yang [3] argued that the cracking process depended on both the fissure geometry and the heat treatment temperature. Chen et al. [4] carried out uniaxial compression experiments on the sandstone samples containing double fissures and a single circular hole and thought that the peak strength, peak strain, and elastic modulus of defected specimens show decreased trend firstly and then increase with changing from $0^{\circ}$ to $90^{\circ}$.

Lu et al. [5] showed that cracked sandstone samples are tension-destructed under uniaxial compression, and the crack propagation directions are consistent with the loading direction. Zou et al. [6] studied the different mechanical and cracking behaviours of single-flawed brittle gypsum 
specimens under dynamic and quasi-static loadings. Under dynamic loadings, a series of shear and tensile cracks compose an "X" shaped crack band which leads to macroscopic failure. Zhang and Wong [7] found that the initiation and propagation of the first cracks did not have a significant influence on the compressive stress singularity at the flaw tips, which was the driving force of the initiation of secondary cracks. Haeri et al. [8] thought that wing cracks are mainly responsible for crack's coalescence and the final crack's propagating paths.

Wang et al. [9] found that wing cracks are more likely to be restrained, and the shear cracks are more likely to occur with an increase in the confining stress because the confining stress hampers the growth of wing cracks. Yang et al. [10] generalized that most of the cracks were observed after peak strength. Yang et al. [11] carried out experimental research through uniaxial compression and found that the peak strain and elastic modulus are not obviously dependent on the coplanar flaw angle. Zhang and Wong [12] revealed that the uniaxial compressive stress and coalescence stress increase significantly, while the first crack initiation stress only subtly increases with the increase of loading rate. Yang et al. [13] believed that the parallel joint interaction had an important dependence on the joint dip angle, joint spacing, and joint overlap. In the failure mode, the paper also argued that the parallel joint planes interact with each other through the wing cracks developed from the preexisting joints. Prudencio and Jan [14] conducted a biaxial experiment that showed that the geometry of the joint systems played a substantial role in the failure modes.

However, the experiments were mainly focused on uniaxial compression, while the rock mass actually is usually under the condition of triaxial compression; triaxial compression, compared with uniaxial compression, is closer to the actual circumstances in which the rock existed and consequently leads to a more accurate result.

Confining pressure has an obvious effect on the deformation parameters [15], with the increment of the confining pressure, Young's modulus increased nonlinearly, but the peak axial strain increased linearly [16], and with the increment of confining pressure, the peak strength and crack damage threshold increase correspondingly [17]. Yang and Huang [18] concluded that, for the same fissure angle, the crack damage threshold and the peak strength of granite both increase with the confining pressure. To investigate the crack behaviour during the sudden unloading process, a series of true triaxial loading and unloading experiments were conducted by Wang et al. [19]. According to their results, as the specimen crack inclination angle increases, the unloading deformation increases. Huang et al. [20] argued that the failure mode was mainly affected by confining pressure when the value is relatively high. The antiwing cracks emanate and propagate strongly at a high confining pressure value. The triaxial compression experiment was carried out on the fracture characteristic of three collinear cracks by Liu et al. [21]. The results show that the critical stresses of cracked specimens change with crack inclination angles, and when the angle is $45^{\circ}$, the critical stress is the lowest; the critical stresses increase with the confining stresses.
These study results on the fracture coalescence behaviour of preexisting fissured rock can shed light on the development of fractured rock mechanics and increase the understanding of the unstable failure mechanism of rock engineering; it plays an important role to figure out the mechanical behaviour and deformation characteristics of fractured rock-like material under triaxial compression; however, these results have not reached an agreement on it. In this paper, the mechanical characteristics and deformation behaviour of fractured rocklike material with a single fissure will be reported. Based on the triaxial compression results and numerical simulation FLAC $^{3 \mathrm{D}}$, we investigate the dependence of the mechanical characteristics and deformation behaviour on the fissure angle, fissure length, and the confining pressure in detail. This research will deepen the understanding of the mechanical characteristics and deformation behaviour of fractured rocklike material with a single fissure.

\section{Experimental Design}

Triaxial compression is a kind of destructive experiment; the specimen cannot be recovered or reused once it reaches failure, and one single structural plane of the original rock can only be used in one destructive experiment. It is difficult to obtain an original rock sample, and the quantity of original rock specimens can hardly meet the huge needs of engineering experiments. Consequently, to analyse the failure behaviour and influential factors of single fractured rock mass, an artificially manufactured single fractured specimen with different lengths of fissure is needed. The designed inclination of the specimen with a single fracture is $30^{\circ}, 60^{\circ}$, and $90^{\circ}$, and the lengths $A B$ are $12 \mathrm{~mm}, 24 \mathrm{~mm}$, and $36 \mathrm{~mm}$, respectively.

2.1. Experimental Material and Specimen Manufacture. The deep-buried marble from the JinPing Stage Two Hydropower Station is used as an original rock specimen. According to the selection principle of similar material and the similarity theory, high-strength silica mortar material is adopted as simulation material of the brittle marble buried deep, and a high-strength thin steel sheet with a thickness of $0.2 \mathrm{~mm}$ is used to make an open fissure in the specimen.

Figure 1(a) is the location map of the mould and fissure. Figure 1(b) is the pouring material in the mould. For the orthogonal experiment, a series of proportioning tests are carried out to ensure the mix ratio of the highstrength silica powder mortar material, which is ordinary Portland cement:microsilicon powder:quartz sand:iron powder:high efficiency water-reducing agent: water = $1: 0.13: 0.8: 0.25: 0.02: 0.325$ (quality ratio).

The physical and mechanical properties tests are conducted on an intact specimen with no fissure and the prototype of marble, obtaining the parameters exhibited in Table 1 . The similarity constants of the specimen and prototype are shown in Table 2. $C_{\gamma}, C_{E}, C_{\mu}, C_{\mathrm{RC}}, C_{\mathrm{pt}}, C_{c}$, and $C_{\varphi}$ represent the similarity constants of the density, elastic modulus, Poisson's ratio, compression strength under 
TABLE 1: Physical-mechanical properties of silicon powder mortar and marble.

\begin{tabular}{|c|c|c|c|c|c|c|c|}
\hline \multirow[t]{2}{*}{ Material } & Density & $\begin{array}{c}\text { Elastic } \\
\text { modulus }\end{array}$ & $\begin{array}{l}\text { Poisson's } \\
\text { ratio }\end{array}$ & $\begin{array}{l}\text { Compression } \\
\text { strength }\end{array}$ & $\begin{array}{l}\text { Tensile } \\
\text { strength }\end{array}$ & Cohesion & $\begin{array}{c}\text { Internal } \\
\text { friction angle }\end{array}$ \\
\hline & $/ \mathrm{g} / \mathrm{cm}^{-3}$ & $/ \mathrm{GPa}$ & $\mu$ & $/ \mathrm{MPa}$ & $/ \mathrm{MPa}$ & $/ \mathrm{MPa}$ & $1^{\circ}$ \\
\hline Model & 2.207 & 14.19 & 0.12 & 70.12 & 2.16 & 20.73 & 35 \\
\hline Prototype & 2.7 & 25.20 & 0.14 & 199.2 & 5.57 & 61.13 & 35.8 \\
\hline
\end{tabular}

TABLE 2: Similarity constant of physical-mechanical parameters of prototype specimen and model.

\begin{tabular}{lccccccc}
\hline Similar constant & $C_{\gamma}$ & $C_{E}$ & $C_{\mu}$ & $C_{\mathrm{RC}}$ & $C_{\mathrm{Pt}}$ & $C_{c}$ & $C_{\varphi}$ \\
\hline Prototype/model & 1.22 & 1.78 & 1.17 & 2.84 & 2.58 & 2.95 & 1.02 \\
\hline
\end{tabular}

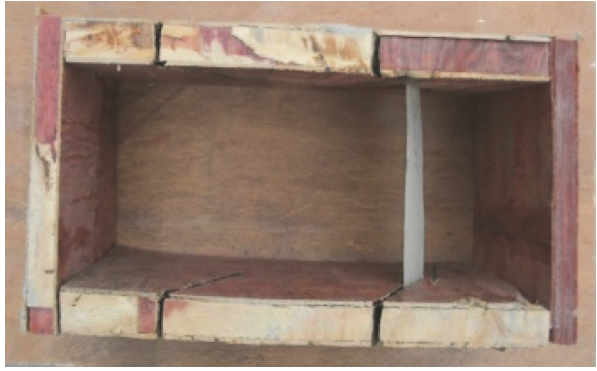

(a)

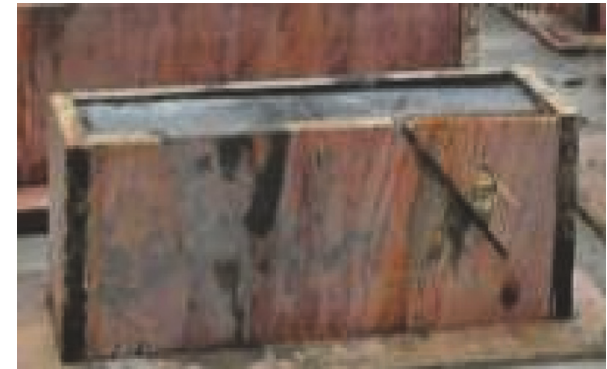

(b)

FIGURE 1: Mould and material of modelling.

uniaxial compression, tensile strength, cohesion, and friction coefficient. The relations between them are as follows:

$$
\begin{aligned}
& C_{\gamma} \approx C_{\mu} \approx C_{\varphi}=1, \\
& C_{E} \approx C_{\mathrm{RC}} \approx C_{\mathrm{pt}} \approx C_{c} .
\end{aligned}
$$

The compression and tensile strength of the high-strength silica mortar material are up to 32.5 with good brittleness. The physical and mechanical properties of the mould material are much closer to the properties of the prototype marble because the similarity constants meet the similarity theory. The mould material has the advantages of a stable nature, is easily obtained, and has no dependence on the outside environment. The mould material, as a substitute for prototype rock, can almost perfectly simulate its deformation characteristics under triaxial loading compression.

2.2. Experimental Condition and FLAC ${ }^{3 D}$ Numerical Simulation. The experiment is performed on the MTS815.03 electrohydraulic servo rock testing machine in Shandong University of Science and Technology and is controlled by computer during the whole process. The confining pressure is controlled by strain while the axial pressure is controlled by the displacement. The designed confining pressures are 7, 14, and $21 \mathrm{MPa}$. The completed intact specimens and fractured specimens are exhibited in Figure 2.

FLAC $^{3 \mathrm{D}}$ is a three-dimensional finite-difference computer codes for geomechanics application. And it is widely used in the field of geotechnical engineering. FLAC ${ }^{3 \mathrm{D}}$ is used to simulate the influence of the fissure and confining pressure on the mechanical and deformation behaviour of fractured rock-like material in this paper.

\section{Experimental and Numerical Results and Analysis}

The parameters and terms in this paper are as follows: $\alpha$ is the angle between the fractures plane; minimum stress is $\sigma_{3}$, simply called fissure angle; $\mathrm{AB}$ is the length of fissure in the $\sigma_{1}-\sigma_{3}$ plane $2 \mathrm{a}$, simply called the length of fissure; $\beta$ is the inclination between the $\mathrm{AB}$ direction and the axial compression $\sigma_{1}$. The peak strength is the deviatoric stress when the failure occurs to the specimen while the residual strength is the deviatoric stress when the specimen enters into the ductility stage under triaxial compression. The slope of the connection of the $30 \%$ peak strength point and $70 \%$ peak strength point on the stress-strain curve is defined as elastic modulus; the ratio of corresponding difference of circumferential strain and the difference of axial strain is defined as the value of Poisson's ratio. The deformation modulus is defined from the secant slope at the value of $50 \%$ peak strength in the stress-strain curve.

3.1. Analysis of Experimental Research on Mechanical Characteristics. The results of triaxial compression experiments on 
TABLE 3: Results of the triaxial compression tests about these single jointed specimens.

\begin{tabular}{|c|c|c|c|c|c|c|c|}
\hline $\begin{array}{l}\text { Specimen } \\
\text { number }\end{array}$ & $\begin{array}{c}\text { Inclination } \\
1^{\circ} \\
\end{array}$ & $\begin{array}{c}\text { Fissure length } \\
\quad / \mathrm{mm}\end{array}$ & $\begin{array}{c}\text { Confining } \\
\text { pressure } \\
/ \mathrm{MPa} \\
\end{array}$ & $\begin{array}{c}\text { Peak stress } \\
\text { /Mpa } \\
\end{array}$ & $\begin{array}{c}\text { Elastic } \\
\text { modulus } \\
/ \mathrm{GPa}\end{array}$ & $\begin{array}{c}\text { Deformation } \\
\text { modulus } \\
/ \mathrm{GPa}\end{array}$ & $\begin{array}{c}\text { Residual } \\
\text { strength } \\
/ \mathrm{MPa}\end{array}$ \\
\hline $\mathrm{A} 0-1$ & 0 & 12 & 14 & 67.73 & 13.899 & 6.121 & 83.44 \\
\hline A1-1 & 30 & 12 & 14 & 68.67 & 13.738 & 6.778 & 69.28 \\
\hline A2-5 & 60 & 12 & 7 & 82.50 & 14.745 & 10.011 & 46.69 \\
\hline A2-1 & 60 & 12 & 14 & 85.86 & 14.859 & 8.586 & 59.87 \\
\hline A2-4 & 60 & 12 & 21 & 93.58 & 15.011 & 7.830 & 27.02 \\
\hline $\mathrm{C} 2-7$ & 60 & 36 & 7 & 46.5 & 5.109 & 3.037 & 31.25 \\
\hline C2-1 & 60 & 36 & 14 & 68.08 & 6.444 & 4.018 & 59.03 \\
\hline $\mathrm{C} 2-3$ & 60 & 36 & 21 & 88.59 & 7.018 & 7.237 & 74.93 \\
\hline A3-4 & 90 & 12 & 7 & 87.00 & 15.494 & 10.531 & 54.02 \\
\hline A3-3 & 90 & 12 & 14 & 98.60 & 15.152 & 9.456 & 68.30 \\
\hline A3-6 & 90 & 12 & 21 & 93.27 & 14.233 & 8.742 & 33.22 \\
\hline B3-2 & 90 & 24 & 14 & 112.6 & 15.532 & 10.166 & 80.44 \\
\hline C3-1 & 90 & 36 & 14 & 103.8 & 15.64 & 8.988 & 91 \\
\hline
\end{tabular}
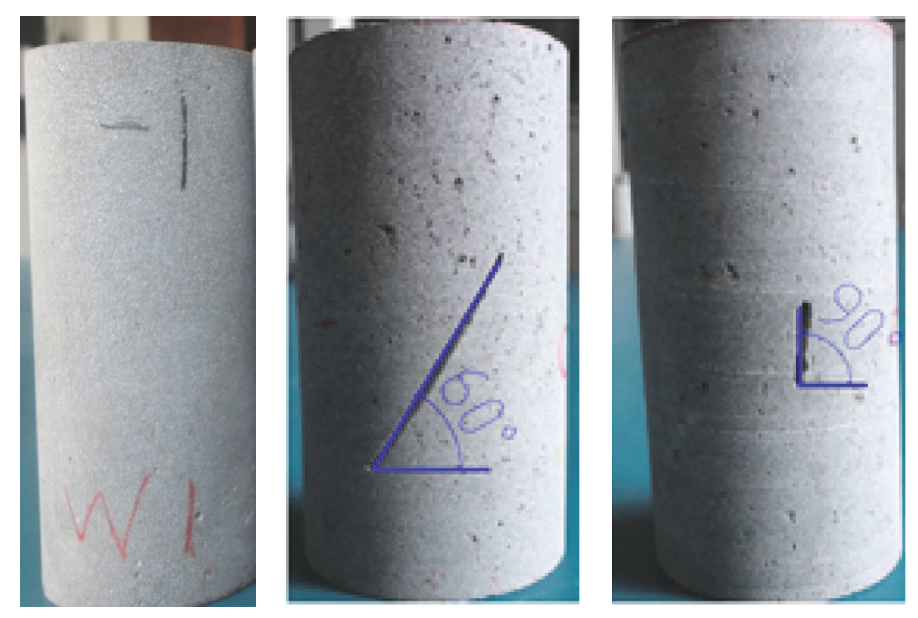

FIgURE 2: The intact specimen and single jointed specimens.

the specimen with different confining pressures are exhibited in Table 3. The axial stress-strain relationships of the A2, $\mathrm{C} 2$, and $\mathrm{A} 3$ series when the confining pressure values are 7 , 14 , and $21 \mathrm{Mpa}$, respectively, show that the A2-4 specimens are substantially immersed in the grease while the A3-6 specimens are completely immersed.

The following characteristics can be analysed from Table 3 and Figure 3: (1) immersion in grease will strongly influence the strength characteristics of a specimen during the experimental process. The peak strength and residual strength decrease with grease immersion before peak strength (see A3-6) while the residual strength will rarely decrease with grease immersion after the peak strength (see A2-4). (2) The peak strength of fractured specimens with one single fissure increases with the increase in the confining pressure when fissure angle and the length of the fissure are constant (the series of A2 and C2). The residual strength also increases with rising confining pressure. (3) The peak strength decreases with an increase in the length of the fissure when the inclination of the fissure and the confining pressure are constant (see the series of A2 C2). (4) The peak strength of the specimen increases along with the rise of fissure angle for a constant value of length of fissure and confining pressure. (5) The confining pressure has a distinct effect on the ductility characteristics of the specimen. (6) "A distinct stress drop" occurs in the early stage of the stress-strain curve when the length fissure is relatively long (see the series of C2).

The relationship of the circumferential strain and axial strain is shown in Figure 4 when the values of the fissure length and confining pressure are constant at $12 \mathrm{~mm}$ and $14 \mathrm{Mpa}$, respectively, while the fissure angle varied from $0^{\circ}$ to $90^{\circ}$ with an interval of $30^{\circ}$. There is an intact specimen 


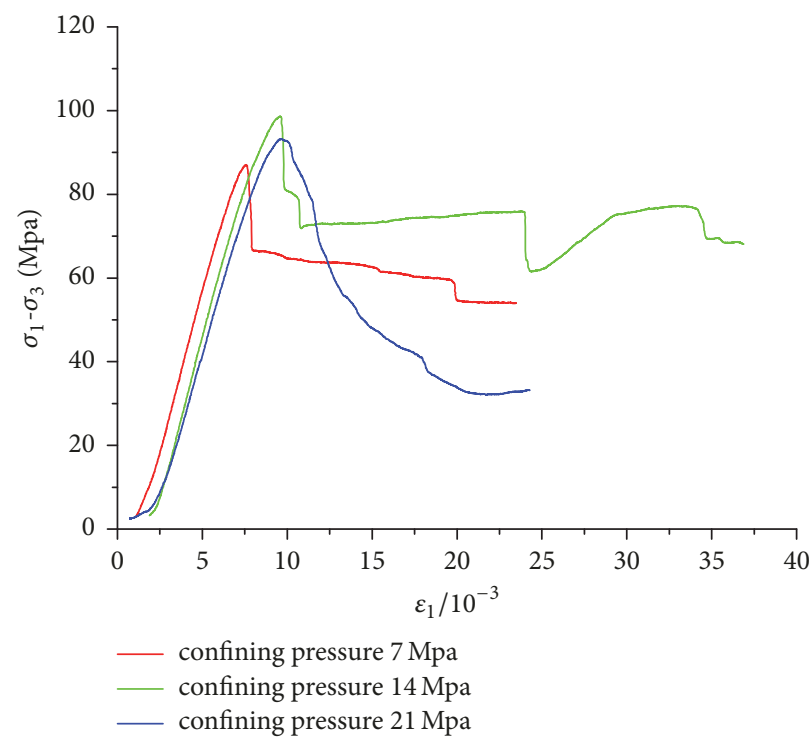

(a) A2

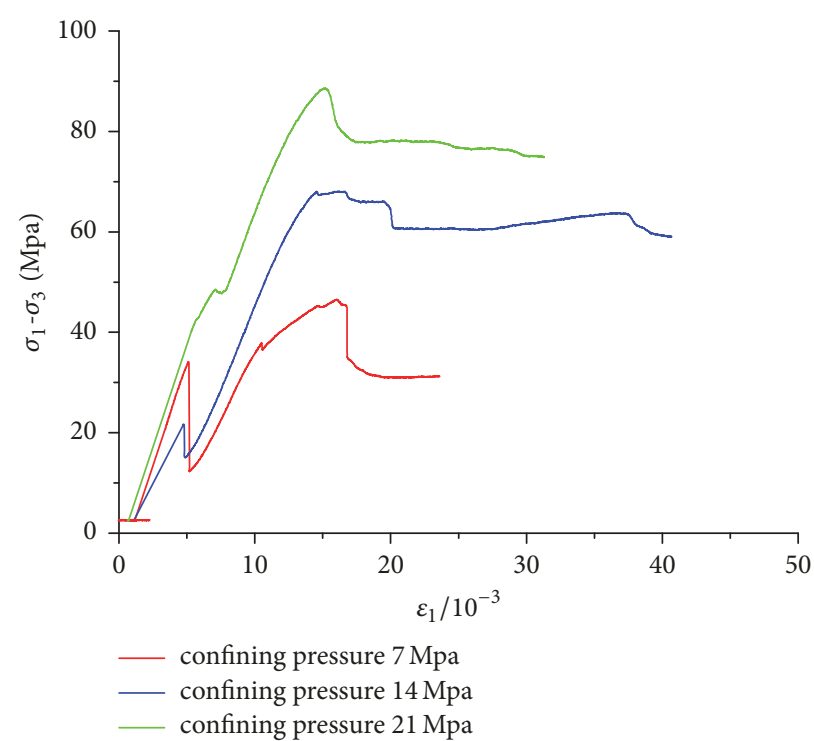

(b) $\mathrm{C} 2$

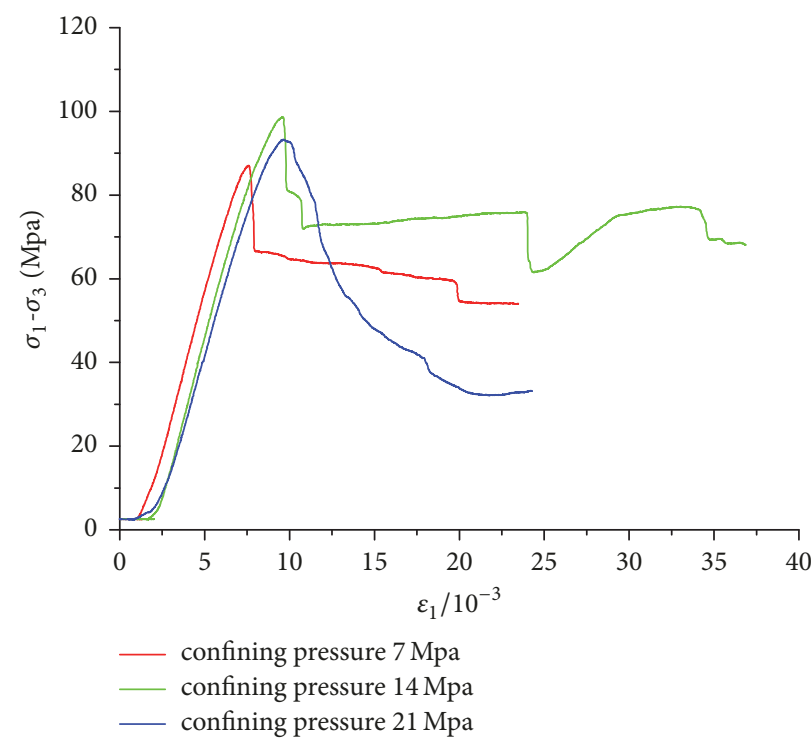

(c) A3

FIgURE 3: Axial stress-strain curves of single jointed specimens.

contained for contrast. To better analyse the relationship of the circumferential strain and axial strain of the rocklike material specimen with a conventional compression experiment, the Poisson coefficient is defined as the ratio of the circumferential strain and axial strain at any time during the experiment. By analysing Figure 3 , the following conclusions are obtained: (1) the Poisson coefficient of the contact specimen equals the specimen whose angle is $90^{\circ}$ and (2) the value of the Poisson coefficient decreases when the fissure angle increases from $0^{\circ}$ to $60^{\circ}$ with an increment of $30^{\circ}$.

3.2. Analysis on $F L A C^{3 D}$ Numerical Simulation. $F_{L A C}{ }^{3 D}$ is used to simulate failure behaviour of fractured rock-like material under triaxial compression; the relationship of axial stress and axial displacement under triaxial compression is shown in Figure 5. The following characteristics can be analysed from Figure 5: (1) On the one hand, fissure length has an important impact on the peak strength of fractured rock-like material; that is, with the increase of fissure length, the peak strength shows a decreasing tendency; the existence of fissure greatly weaken the strength characteristics of rocklike material; on the other hand, the fissure length has little effect on the residual strength. (2) Before the peak strength, three axial stress-displacement curves are almost coincided with each other. (3) The confining pressure plays a substantial role in influencing peak strength of fractures rocklike material, when the confining pressure is relatively high, the peak strength and residual strength of fractured specimen are relatively high. 


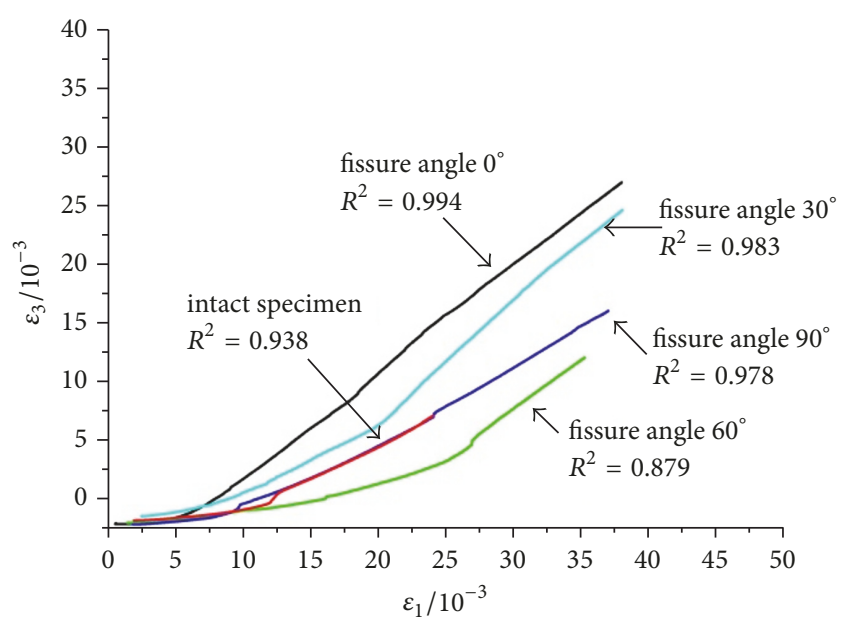

FIGURE 4: Relationship of the circumstantial strain and axial strain.

\section{Failure Behaviour}

4.1. Influence of Fissure Angle on the Failure Behaviour. The typical failure modes of the specimen are shown in Figure 6 when the values of the confining pressure and the fissure length are constant, and the inclination is varied from $0^{\circ}$ to $90^{\circ}$ with an increment of $15^{\circ}$.

By analysing Figure 6, when the value of the confining pressure and fissure length are constant while the inclination of the fissure is varied from $0^{\circ}$ to $90^{\circ}$ with an increment of $15^{\circ}$, the failure behaviour is as follows: (1) the macroscopic failure mode of each specimen is mainly " $\mathrm{X}$ " shear failure that is composed of the ")" shaped (1) wing crack and the "(" shaped (2) antiwing crack formed from the tips of the fissure. (2) The (3) tensile crack, called I-crack, developed from the middle of the fissure or the extension direction of the middle of the fissure of each specimen, is paralleled to the principal stress direction. With the increment of the inclination of the fissure, the angle between the I-crack and the principal stress decreases. (3) When the fissure angle is relatively small ( $\alpha$ $=0^{\circ}, 30^{\circ}$ ), an intensive fractured zone emerged around the preexisting fissure, indicating that the stress distribution is complicated there. Two distinct antiwing fractures developed from the one tip of the prefissure; the stress state is relatively simple when the fissure angle is relatively high $\left(\alpha=60^{\circ}, 90^{\circ}\right)$. The stress state is relatively simple, and the failure mode is focused on mainly shear failure. (4) Whether the extension of the wing crack and antiwing crack or the extension of the tensile crack is more likely to develop to the side of the specimen instead of extending to the top or bottom end of the specimen, thus forming the "petal-type" crack (III-crack), the range of "III-crack" is increasingly extensive with the increase of the inclination.

4.2. Influence of Fissure Length on the Failure Behaviour. The front view and lateral view of failure figure of the specimen when the values of the confining pressure and the fissure angle are $14 \mathrm{Mpa}$ and $90^{\circ}$, respectively, and when the lengths of the fissure are 12, 24, and $36 \mathrm{~mm}$, are shown in Figure 7.
There are three conclusions generalized from Figure 7: (1) the macroscopic failure modes of the specimens are focus on "X" type shear failure composed of ")" shaped (1) wing crack and "(" shaped (2) antiwing crack. The angle between the wing crack and antiwing crack increases with the increment of the fissure length. (2) When the length of the fissure is relatively small, the preexisting fissure is reset under the function of the principal stress and minimum principal stress, and the failure mode is " $\mathrm{X}$ " type shear failure. The tensile crack developed from the middle of the reset preexisting fissure is parallel to the principal stress. When the length of the fissure is relatively long, there is no reset phenomenon of the preexisting fissure and no tensile crack. (3) By analysing the lateral view of the III-crack trace, the field of the III-crack decreases with the increment of preexisting length of the fissure.

4.3. Influence of Confining Pressure on Failure Behaviour. The failure modes of the specimen are displayed in Figure 8 when the values of the preexiting fissure length and the inclination of the fissure are constant at $12 \mathrm{~mm}$ and $90^{\circ}$, respectively, and when the confining pressure varies from $7 \mathrm{Mpa}$ to $21 \mathrm{Mpa}$ with an increment of $7 \mathrm{Mpa}$.

The following conclusions can be obtained by analysing Figure 8: (1) the fissure angles of three specimens whose fissure lengths are $12 \mathrm{~mm}$ have been reset to different extents by the function of principal stress and minimum stress. There are close relationships between the failure modes and the confining pressure; the failure mode is focused on a comprehensive failure containing shear and tensile cracks when the value of the confining pressure is relatively low $\sigma_{3}=$ $7 \mathrm{Mpa}$. The failure mode manifests as " $\mathrm{X}$ "-shaped macroshear failure and I-cracks that are basically parallel to the principal stress when the confining pressure is $14 \mathrm{Mpa}$, while the failure mode manifests as shear failure along the preexisting fissure plane when the confining pressure is $21 \mathrm{Mpa}$. (2) The macrocracks in the front view of the sample A3-6 are focused on wing cracks, and no antiwing cracks' trace is found. The "petal"-shaped crack in the lateral view has only half trace because the holistic shear failure develops from one end surface to the lateral surface.

The failure modes of the specimen are shown in Figure 9, where the values of the fissure length and the fissure angle are constant at $12 \mathrm{~mm}$ and $60^{\circ}$, respectively, and the values of the confining pressure vary from $7 \mathrm{Mpa}$ to $21 \mathrm{Mpa}$ with an increment of $7 \mathrm{Mpa}$. As shown in Figure 9, the trace of crack propagation is smoothing with the increment of the confining pressure, and the mainly macrofailure plane of the specimen manifests as holistic shear failure- " $X$ "-shaped shear failure-pure shear failure. Similar to Figure 8, the holistic shear crack of the specimen A2-4 propagates from one end to the lateral surface when the confining pressure is relatively high; thus there is only a half crack trace of the "petal" crack in the lateral surface. However, when the confining pressure is relatively low, the crack propagates from one end to the other with no III-crack in the lateral surface and with no consideration of the influence of the end effect.

The failure behaviours of the varied specimens in Figures $6,7,8$, and 9 are analysed comprehensively, indicating the 


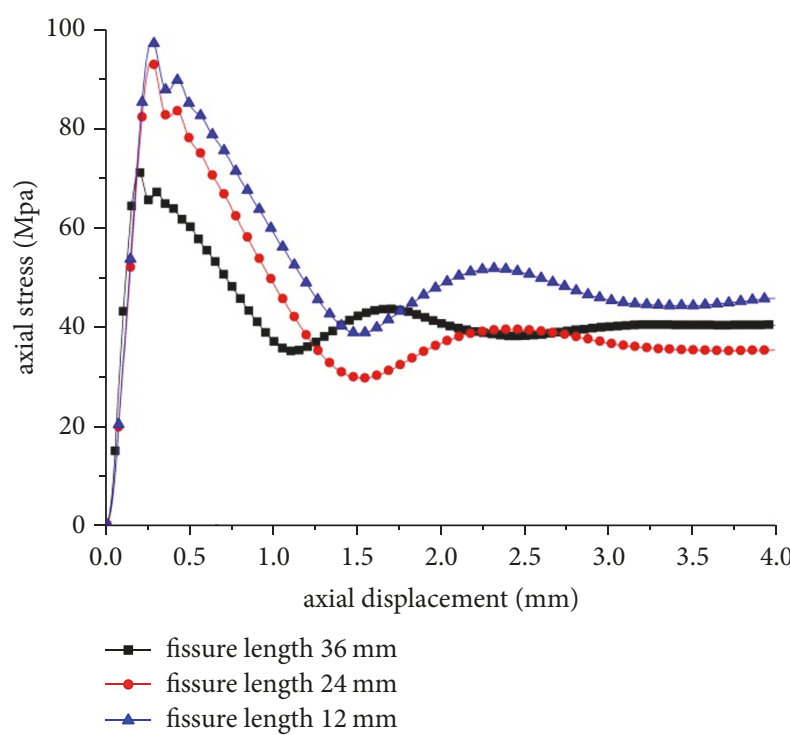

(a) The confining pressure and fissure angle are constant while fissure length is varied from $12 \mathrm{~mm}$ to $36 \mathrm{~mm}$ with an interval of $12 \mathrm{~mm}$

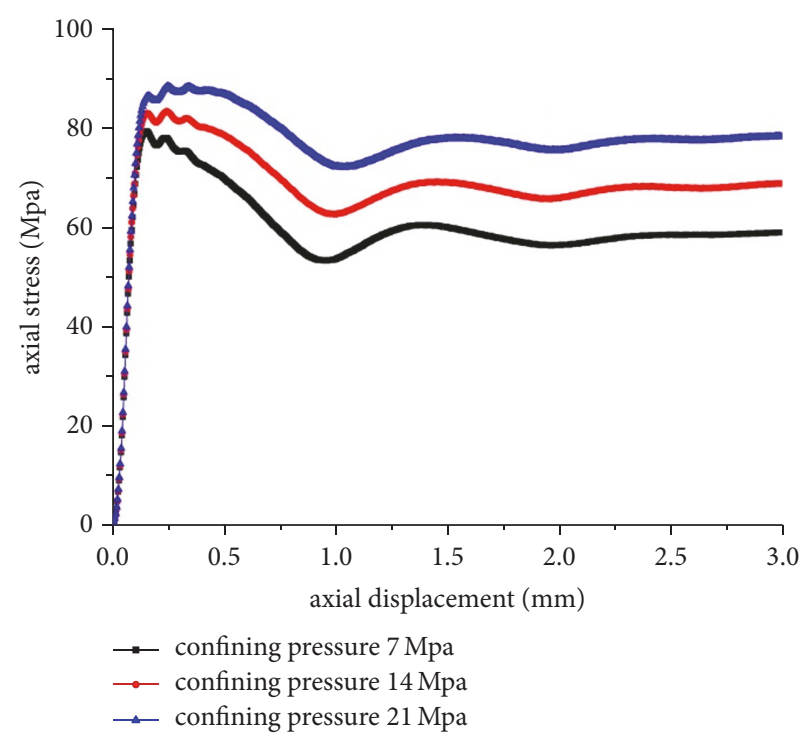

(b) The fissure length and fissure angle are constant while confining pressure is varied from $7 \mathrm{Mpa}$ to $21 \mathrm{Mpa}$ with an interval of $7 \mathrm{Mpa}$

FIGURE 5: Relationship of axial stress and axial displacement.

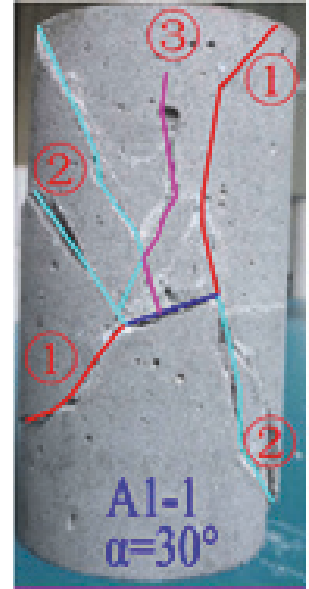

(A) A0-1, $\alpha=0^{\circ}$

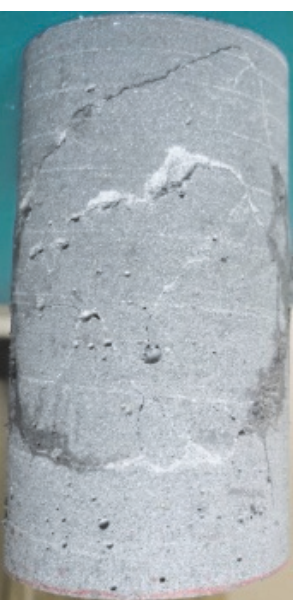

(A)

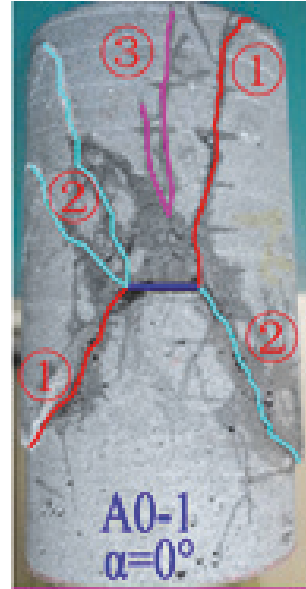

(B) A1-1, $\alpha=30^{\circ}$

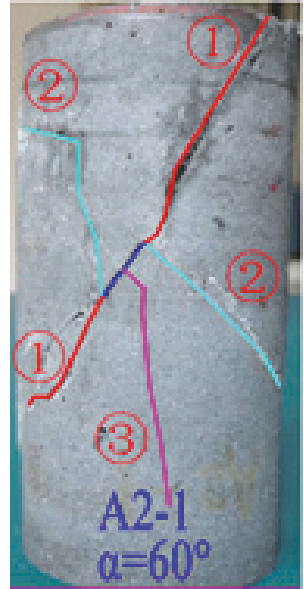

(C) A2-1, $\alpha=60^{\circ}$

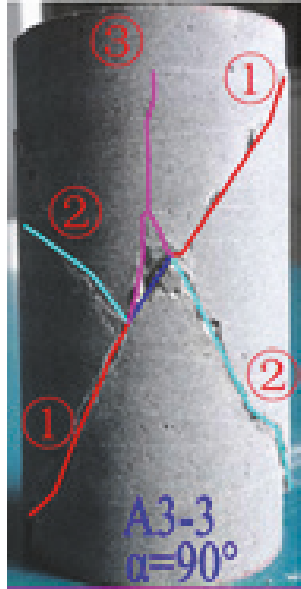

(D) A3-3, $\alpha=90^{\circ}$

(a) Front view

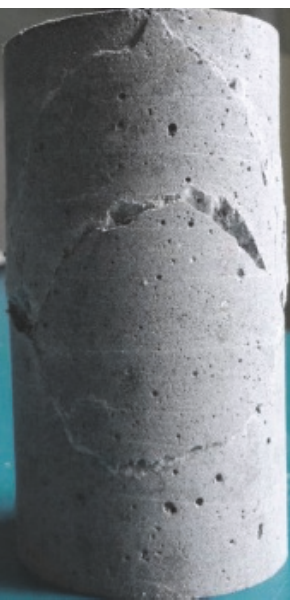

(B)

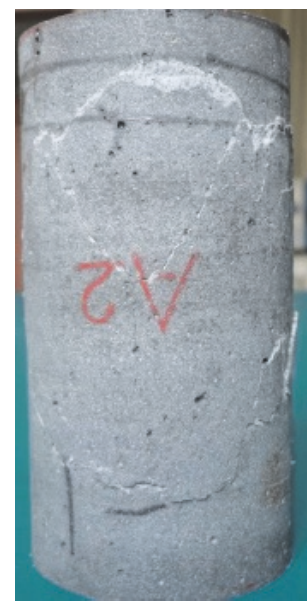

(C)

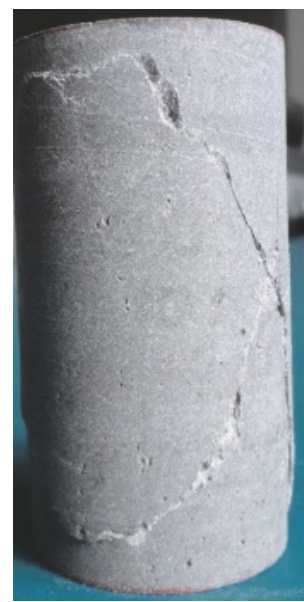

(D)

(b) Lateral view

Figure 6: Fracture modes of specimens with different joint inclination. 


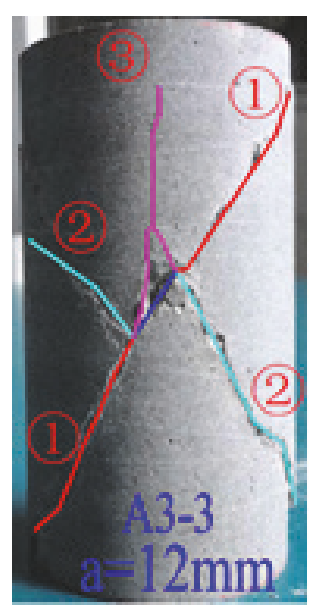

(A) A3-3, $a=12 \mathrm{~mm}$

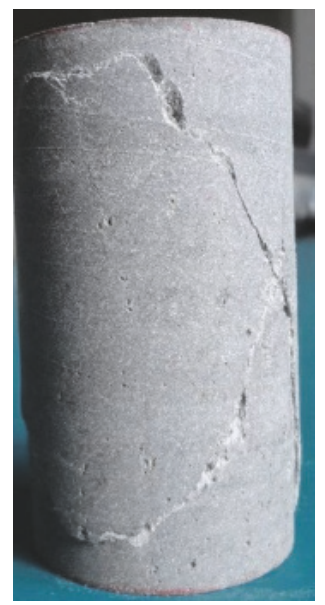

(A)

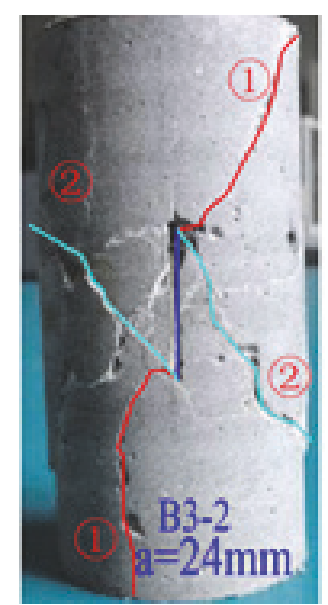

(B) B3-2, $a=24 \mathrm{~mm}$

(a) Front view

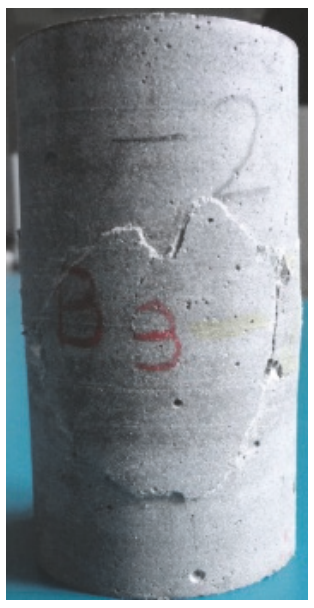

(B)

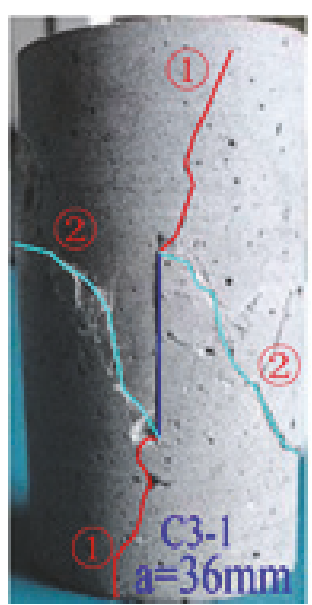

(C) C3-1, $a=36 \mathrm{~mm}$

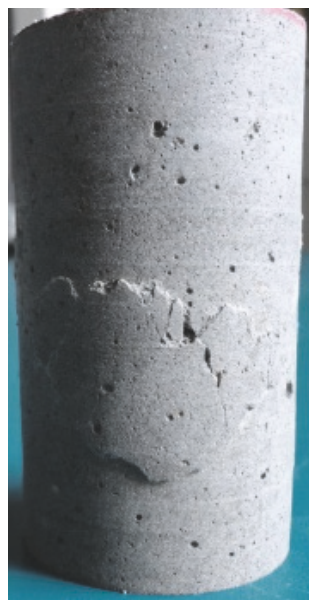

(C)

(b) Lateral view

FIgURE 7: Fracture modes of specimens with different joint lengths.

following: (1) the macrofailure of the specimen is focused on "X"-shaped shear failure with the conventional compression experiment on the rock-like material with one single fissure. Pure shear failure occurs under specific conditions; the tensile crack which parallels the principal stress emerges in some of the specimens whose comprehensive failure characteristics containing shear failure and tensile failure are obvious. (2) The wing cracks and antiwing cracks, observed by many scholars under uniaxial compression or biaxial compression experiments, are surface traces formed of III-crack from triaxial compression. (3) In the conventional compression experiment on rock-like material with one single fissure, the III-crack is universal, and the lateral slip and contact zone slip of the three-dimensional fissure probably play an important role in the process of the crack initiation, coalescence, and propagation of the III-crack. (4) The III-crack composed of the extension trajectory of the wing crack and antiwing crack looks like a petal. The wing crack and antiwing crack hardly can develop to the ends of the specimen in the experiment of the three-dimensional fissure. (5) The crack propagation law of the rock-like material specimen with one single fissure is closely related to the preexisting fissure under conventional compression; the confining pressure plays an essential part in the macrofailure modes; however, the scale of the crack propagation, that is, the propagation trace of the wing crack and antiwing crack, is dependent on the length of the fissure. The preexiting fissure is the inducement for crack initiation.

\section{Conclusions}

The aim of this experimental study is to investigate the mechanical characteristics and deformation behaviour of the rock-like material specimen containing a single fissure under triaxial compression. On the basis of the experimental results 


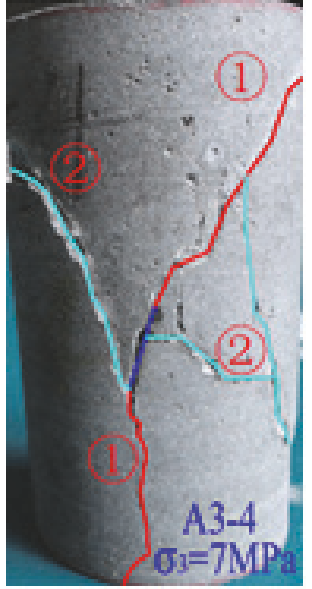

(A) $\mathrm{A} 3-4, \sigma_{3}=7 \mathrm{MPa}$

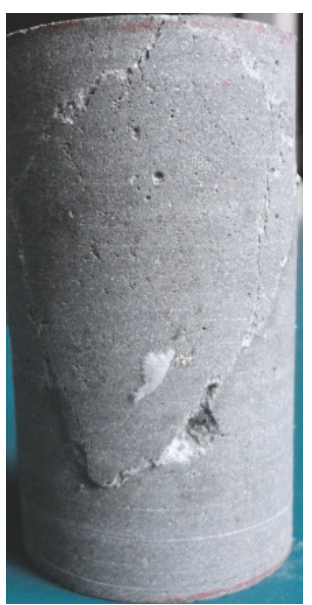

(A)

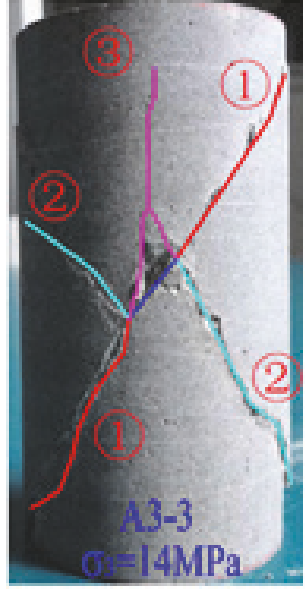

(B) $\mathrm{A} 3-3, \sigma_{3}=14 \mathrm{MPa}$

(a) Front view

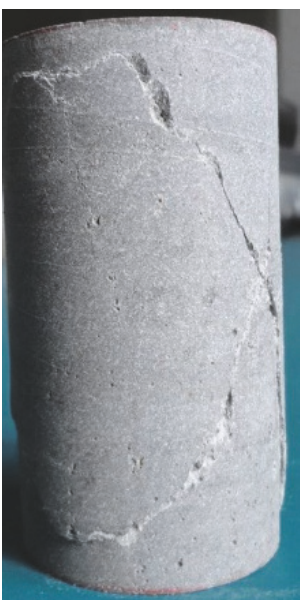

(B)

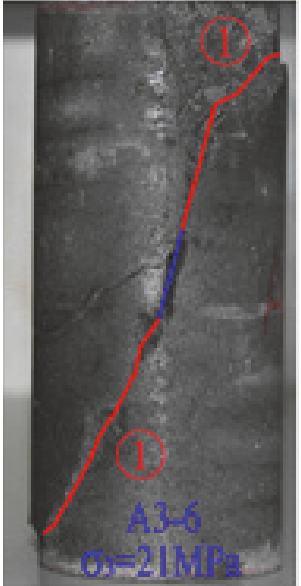

(C) $\mathrm{A} 3-6, \sigma_{3}=21 \mathrm{MPa}$

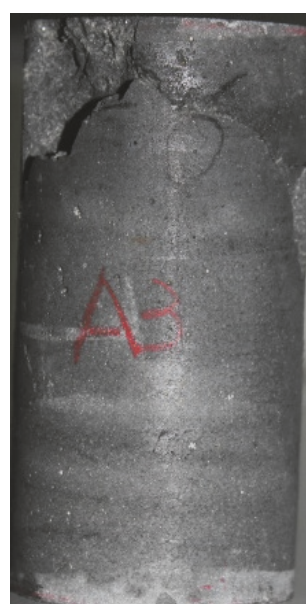

(C)

(b) Lateral view

FIGURE 8: Fracture modes of specimens with different confining pressures.

and FLAC $^{3 \mathrm{D}}$ numerical simulation analysis, the following conclusions can be drawn:

(1) The peak strength of fractured specimens with one single fissure increases with the increment of the confining pressure when fissure angle and the length of fissure are constant, while it decreases with the increase in the length of fissure when the inclination of the fissure and the confining pressure are constant. The peak strength increases along with the rise of fissure angle under a constant value of length of fissure and confining pressure; the residual strength increases with the rise of confining pressure.

(2) The confining pressure has a distinct effect on the ductility characteristics of the specimen. "A distinct stress drop" occurred in the early stage of the stress-strain curve when the length of the fissure is relatively long.

(3) The Poisson coefficient of the contact specimen equals that of the specimen whose angle is $90^{\circ}$; the value of the Poisson coefficient decreases when the fissure angle increases from $0^{\circ}$ to $60^{\circ}$ with an increment of $30^{\circ}$.
(4) The I-crack, II-crack, and III-crack are all observed in the triaxial compression; the III-crack is commonly observed in triaxial compression.

(5) There are three kinds of failure modes in the triaxial compression experiment on a rock-like material specimen with one single fissure: tensile-shear comprehensive failure, "X"-shaped shear failure, and shear failure along the fissure plane. Confining pressure plays an essential role in the failure mode of the specimen; the failure mode of the specimen has a tendency to move from tensile-shear comprehensive failure to "X"-shaped shear failure to shear failure along the fissure plane with increments of the confining pressure.

(6) The inclination of the preexisting fissure is a key factor that influences the crack initiation of the specimen; however, the length of the fissure mainly affects the propagation scale of the crack. The field of the III-crack enlarges with the increase of the fissure angle, while, with the increase of fissure length, the field of the III-crack decreases. 


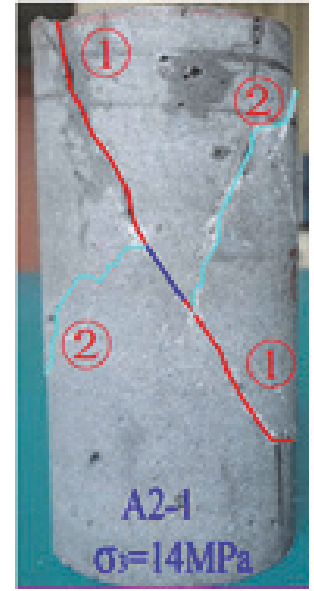

(a) $\mathrm{A} 2-5, \sigma_{3}=7 \mathrm{MPa}$
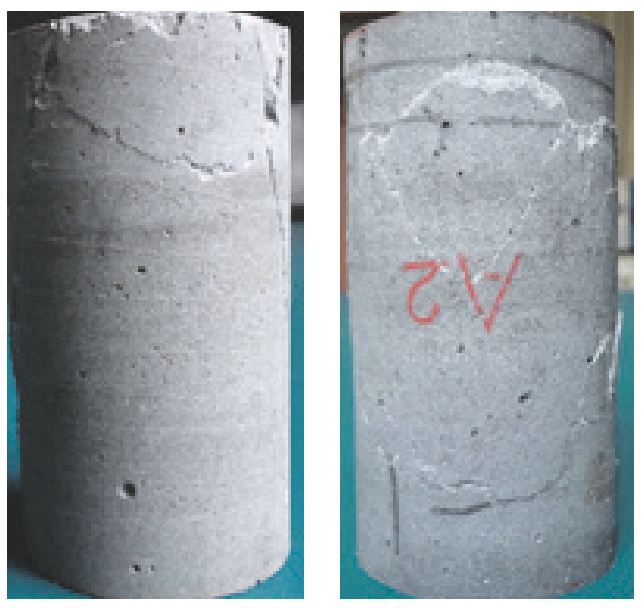

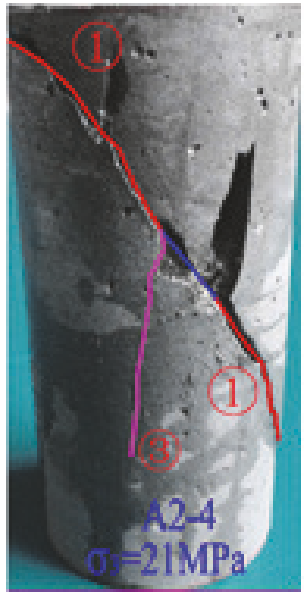

(c) $\mathrm{A} 2-4, \sigma_{3}=21 \mathrm{MPa}$

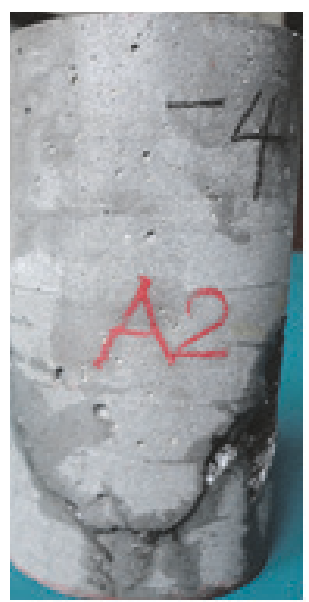

FIgURE 9: Fracture modes of specimens with different confining pressures.

\section{Conflicts of Interest}

The authors declare that there are no conflicts of interest regarding the publication of this paper.

\section{References}

[1] S. Q. Yang and H. W. Jing, "Strength failure and crack coalescence behavior of brittle sandstone samples containing a single fissure under uniaxial compression," International Journal of Fracture, vol. 168, no. 2, pp. 227-250, 2011.

[2] J. Jin, P. Cao, Y. Chen et al., "Influence of single flaw on the failure process and energy mechanics of rock-like material[J]," Computers \& Geotechnics, vol. 86, pp. 150-162, 2017.

[3] S. Yang, "Fracture Mechanical Behavior of Red Sandstone Containing a Single Fissure and Two Parallel Fissures After Exposure to Different High-Temperature Treatments," in Strength Failure and Crack Evolution Behavior of Rock Materials Containing Pre-existing Fissures, Springer Environmental Science and Engineering, pp. 157-183, Springer, Berlin, Heidelberg, 2015.

[4] M. Chen, H. Jing, X. Ma, H. Su, M. Du, and T. Zhu, "Fracture evolution characteristics of sandstone containing double fissures and a single circular hole under uniaxial compression,"
International Journal of Mining Science and Technology, vol. 27, no. 3, pp. 499-505, 2017.

[5] Z.-D. Lu, C.-X. Chen, X.-T. Feng, and Y.-L. Zhang, "Strength failure and crack coalescence behavior of sandstone containing single pre-cut fissure under coupled stress, fluid flow and changing chemical environment," Journal of Central South University, vol. 21, no. 3, pp. 1176-1183, 2014.

[6] C. Zou, L. N. Y. Wong, J. J. Loo, and B. S. Gan, "Different mechanical and cracking behaviors of single-flawed brittle gypsum specimens under dynamic and quasi-static loadings," Engineering Geology, vol. 201, pp. 71-84, 2016.

[7] X.-P. Zhang and L. N. Y. Wong, "Cracking processes in rock-like material containing a single flaw under uniaxial compression: a numerical study based on parallel bonded-particle model approach," Rock Mechanics and Rock Engineering, vol. 45, no. 5, pp. 711-737, 2012.

[8] H. Haeri, K. Shahriar, M. F. Marji, and P. Moarefvand, "Cracks coalescence mechanism and cracks propagation paths in rocklike specimens containing pre-existing random cracks under compression," Journal of Central South University, vol. 21, no. 6, pp. 2404-2414, 2014.

[9] Wang, X. Zhou, and X. Xu, "Numerical simulation of propagation and coalescence of flaws in rock materials under compressive loads using the extended non-ordinary state-based 
peridynamics," Engineering Fracture Mechanics, vol. 163, pp. 248-273, 2016.

[10] S.-Q. Yang, Y.-H. Huang, H.-W. Jing, and X.-R. Liu, "Discrete element modeling on fracture coalescence behavior of red sandstone containing two unparallel fissures under uniaxial compression," Engineering Geology, vol. 178, pp. 28-48, 2014.

[11] S.-Q. Yang, Y.-H. Huang, W.-L. Tian, and J.-B. Zhu, "Erratum to: An experimental investigation on strength, deformation and crack evolution behavior of sandstone containing two oval flaws under uniaxial compression (Eng. Geol. (2017) 217: (35-48) (S0013795216302770) (10.1016/j.enggeo.2016.12.004))," Engineering Geology, vol. 226, pp. 326-327, 2017.

[12] X.-P. Zhang and L. N. Y. Wong, "Loading rate effects on cracking behavior of flaw-contained specimens under uniaxial compression," International Journal of Fracture, vol. 180, no. 1, pp. 93-110, 2013.

[13] X.-X. Yang, H.-W. Jing, C.-A. Tang, and S.-Q. Yang, "Effect of parallel joint interaction on mechanical behavior of jointed rock mass models," International Journal of Rock Mechanics and Mining Sciences, vol. 92, pp. 40-53, 2017.

[14] M. Prudencio and M. V. S. Jan, "Strength and failure modes of rock mass models with non-persistent joints," International Journal of Rock Mechanics and Mining Sciences, vol. 44, no. 6, pp. 890-902, 2007.

[15] S.-Q. Yang, "Strength and deformation behavior of red sandstone under multi-stage triaxial compression," Canadian Geotechnical Journal, vol. 49, no. 6, pp. 694-709, 2012.

[16] S.-Q. Yang, H.-W. Jing, and S.-Y. Wang, "Experimental investigation on the strength, deformability, failure behavior and acoustic emission locations of red sandstone under triaxial compression," Rock Mechanics and Rock Engineering, vol. 45, no. 4, pp. 583-606, 2012.

[17] S.-Q. Yang, "Experimental study on deformation, peak strength and crack damage behavior of hollow sandstone under conventional triaxial compression," Engineering Geology, vol. 213, pp. 11-24, 2016.

[18] S.-Q. Yang and Y.-H. Huang, "An experimental study on deformation and failure mechanical behavior of granite containing a single fissure under different confining pressures," Environmental Earth Sciences, vol. 76, no. 10, article no. 364, 2017.

[19] M. Wang, Z. Zhu, and J. Xie, "An experimental study on deformation fractures of fissured rock around tunnels in true triaxial unloads," Advances in Materials Science and Engineering, vol. 2015, no. 2, Article ID 982842, pp. 1-10, 2015.

[20] Y.-H. Huang, S.-Q. Yang, and J. Zhao, “Three-Dimensional Numerical Simulation on Triaxial Failure Mechanical Behavior of Rock-Like Specimen Containing Two Unparallel Fissures," Rock Mechanics and Rock Engineering, vol. 49, no. 12, pp. 47114729, 2016.

[21] J. Liu, Z. Zhu, and B. Wang, "The fracture characteristic of three collinear cracks under true triaxial compression," The Scientific World Journal, vol. 2014, Article ID 459025, 2014. 


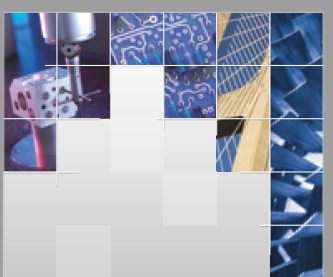

\section{Enfincering}
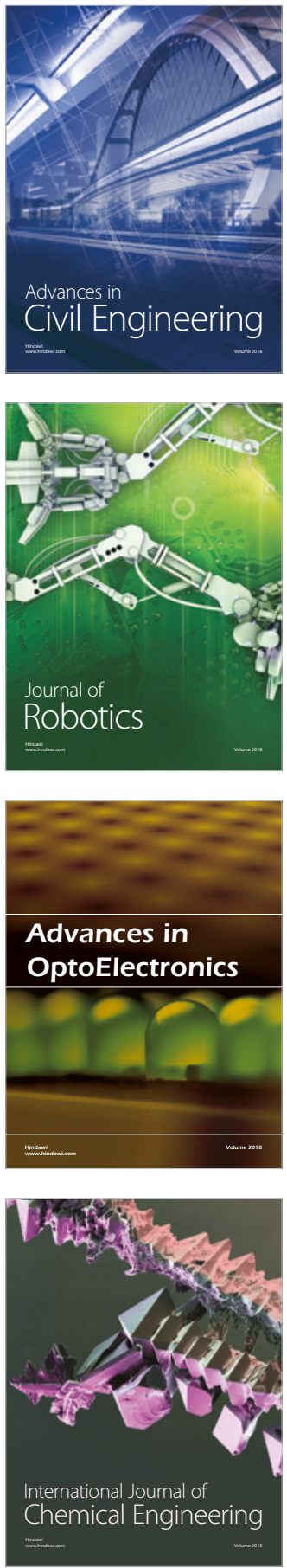

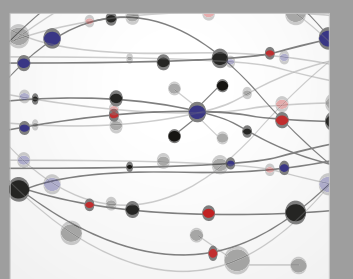

\section{Rotating \\ Machinery}

The Scientific World Journal

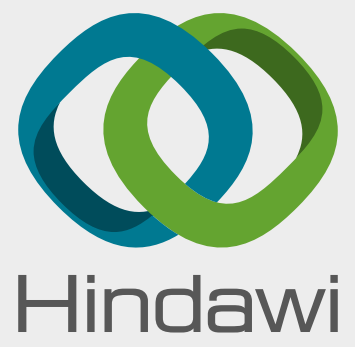

Submit your manuscripts at

www.hindawi.com
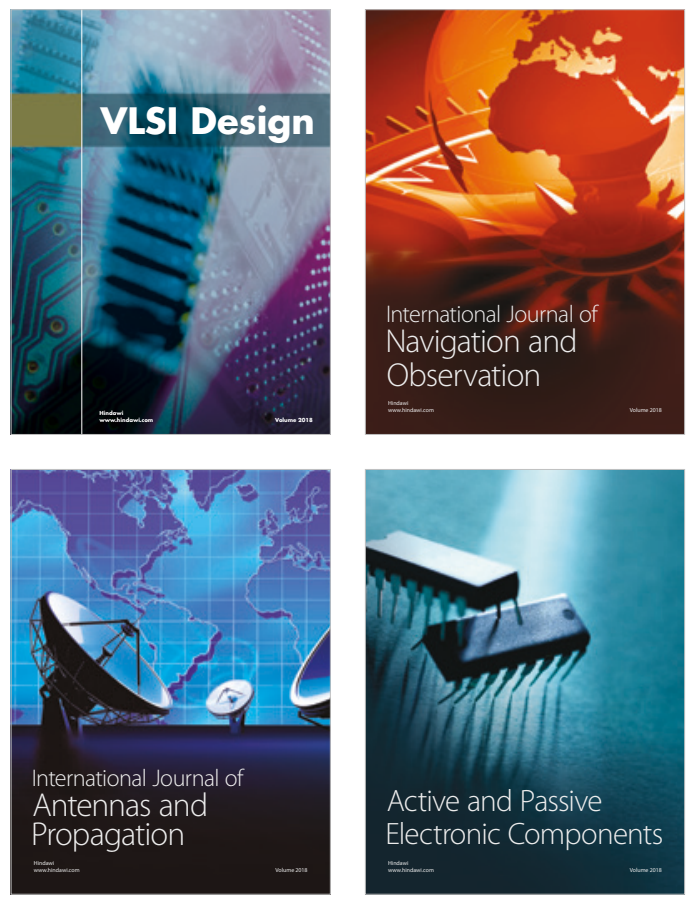
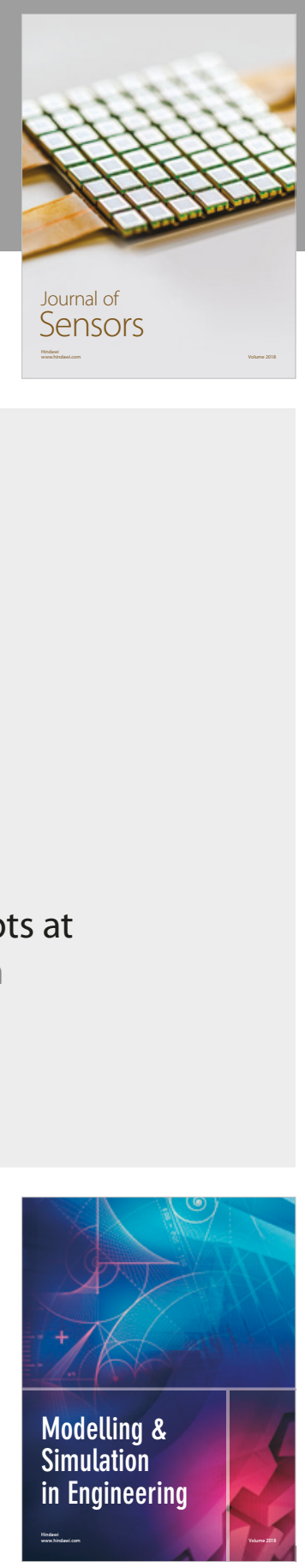

\section{Advances \\ Multimedia}
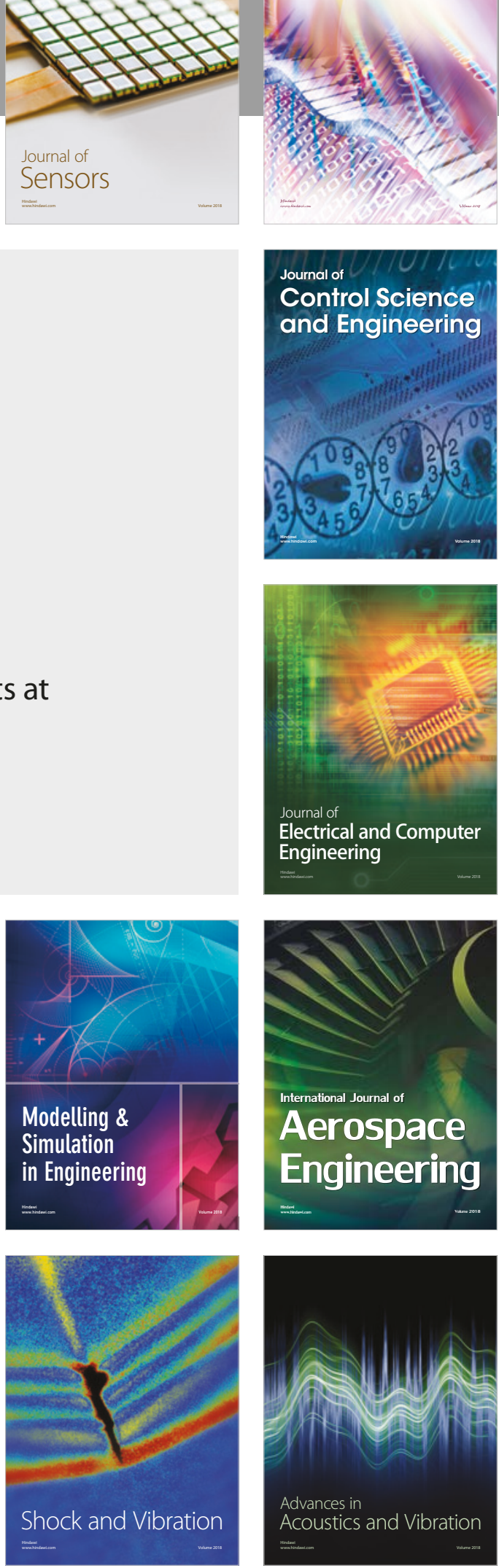